\title{
Study Protocol Document
}

National Cancer Institute

\section{Source}

National Cancer Institute. Study Protocol Document. NCI Thesaurus. Code C93381.

A representation of the study protocol (that persists over time) in document form. 